\title{
ENTRE GÊNEROS TEXTUAIS E REDES SOCIAIS: POSSIBILIDADES INTERATIVAS
}

\author{
BETWEEN TEXTUAL GENRES AND SOCIAL MEDIA: INTERACTIVE POSSIBILITIES
}

\author{
Ana Carolina Almeida de Barros ${ }^{1}$
}

"A sociedade não é constituída por indivíduos, mas expressa a soma das inter-relações, as relações dentro das quais esses indivíduos residem." (Karl Marx, Grundrisse, [1858] 2011)

\begin{abstract}
"[...] Misturam-se as vidas, e assim as pessoas e as coisas misturadas saem cada qual de sua esfera e se misturam: o que é precisamente contrato e a troca. (Marcel Mauss, Ensaio sobre a dádiva, [1950] 2007)
\end{abstract}

“[...] um texto se dá numa complexa relação entre a linguagem, a cultura e os sujeitos históricos que operam nesses contextos. Não se trata de um sujeito individual e sim de um sujeito social que se apropria da linguagem ou que foi apropriado pela linguagem e a sociedade em que vive. (Luiz Antônio Marcuschi. Produção textual, análise de gêneros e compreensão, 2008)

RESUMO: Este artigo é uma tentativa de aproximação entre Linguística e os estudos de Redes Sociais, buscando, em alguma medida, compreender como elas se relacionam, especialmente, quando falamos de gêneros textuais e trocas entre sujeitos, os laços estabelecidos. Recorremos, para as questões de linguagem e gêneros textuais, a Bakhtin (1997), Marcuschi (2008), Koch (2009) e Bawarshi e Reiff (2013); no que tange às Redes Sociais e aos aspectos sociológicos, ancoramo-nos, especialmente, em Emirbrayer (1997) e Mauss (2007). Entendemos, dentro dessa perspectiva que: quanto mais conectados estão os atores, suas interações tornam-se mais dinâmicas, direcionadas e endereçadas, bem como há maior possibilidade de circulação dos constructos textuais, mas não só, pois o senso de convenção é facilitador das interações entre os atores e as trajetórias, além de que o transitado tem poder/influência sobre os agentes, assim como os acessos e lugares ocupados por esses atores dentro de uma estrutura socialmente arranjada.

Palavras-chave: Gêneros textuais. Redes Sociais. Interação.

ABSTRACT: This paper is a way to approach Linguistic and Social Media studies, trying to comprehend how these areas are mixed, in special, when we connect textual genres and interlocutions, to establish connections. For language and textual genres, we evoke Marcuschi (2008), Koch (2009) and Bawarshi e Reiff (2013); about Social Media and sociological perspective: Emirbrayer (1997) and Mauss (2207). We understand that how much more coneccted the language actors are and the constructs textual, the dinamic liguistic is facilitated and has power/influence about the acess and place in the social structure.

Keywords: Textual genres. Social Media. Interaction.

\footnotetext{
I Mestra em Letras, com área de concentração em Linguística, pela Universidade Federal de Pernambuco (2016), atualmente é doutoranda em Linguística na mesma instituição. Possui especialização em Psicopedagogia (2013) e em Linguística Aplicada ao Ensino de Língua Portuguesa. Ambas pela Faculdade Frassinetti do Recife (FAFIRE). É graduada em Letras pela Universidade Federal do Piauí. Orcid:https://orcid.org/oooo-0003-3112-9758
} 


\section{INTRODUÇÃO}

A partir da compreensão de que o mundo não é concebido de maneira isolacionista, préexistente, tampouco fixo e imóvel, entendemos a importância das relações travadas entre os humanos para sua configuração. Essas sempre dinâmicas e heterogêneas relações pautam sentidos e orientam uma unidade, na soma das trocas (EMIRBRAYER, I997; MAUSS, 2007) que só podem ser realizadas passando pelo aspecto da linguagem, daquilo que torna o homem tão único e diferente dos outros seres.

Pensando nesse sujeito tão singular e tão conjunto, esse trabalho foi construído, como uma forma de articular, ainda que de maneira inicial, o caráter da reciprocidade, entre aqueles que percebem a si mesmos, aos outros e o que está em sua volta; parafraseando Donatti (2017), diríamos ser impossível ter a si mesmo, ligar-se ao eu, sem estar com os outros; ainda que as existências e caminhos sejam dados tão pessoalmente, através de suas trajetórias individuais, para serem realizadas, requisitam uma tessitura, um tecido, onde se articulam a histórico, o social, o cultural, o cognitivo e o linguageiro (MARCUSCHI, 2008; KOCH,2009; FALCONE, 2008), em complexos enunciativos-discursivos que marcam as estruturas em solidariedades e alianças (MAUSS, 2007), concretizados em textos através de gêneros, um bem de grande valor simbólico e traço organizativo das rotinas grupais, nos quais cada ator transita.

É, pois, através da articulação desses produtos, constructos culturais, em gêneros textuais, veiculados à rede, ao simbólico, às transações e às interligações, que orientamos nossos dizeres, buscando pontuar como construindo laços, sendo os nós (WHITE apud AZARIAN, 2003; RECUERO, 2014; FONTES \& EICHNER, 200I), estabelecendo conexões, valorando o pode, influenciamos na sedimentação de mundos enunciativosdiscursivos, quando ao apropriarmo-nos de determinadas práticas compartilhadas pela sociedade, tudo entrelaçamos textualmente

\section{GÊNEROS TEXTUAIS: "PRODUTO” DAS INTERAÇÕES VINCULARES}

A percepção e a construção do que envolve o gênero textual - constituição, organização e apropriação pelos grupos sociais - encontram espaço em diversas áreas do saber, como Literatura, Retórica, Análise do Discurso, Ciências Cognitivas e nos estudos desenvolvidos pela Linguística (MARCUSCHI, 2008) e, enquanto objeto de investigação, multiplicidade de abordagens que vão desde um viés formal, como pareciam se 
fundamentar os estudos relacionados aos gêneros literários, até um outro, que se debruça sobre as particularidades do uso e apreensão pelos culturalmente imersos em práticas comunicativas, desde uma abordagem socio-histórica e dialógica, àquela que se constitui em torno da sociorretórica/socio-histórica e cultural (MARCUSCHI, 2008).

É importante trazer à materialidade o que, para nós, reflete uma concepção valiosa de língua ao falarmos de gênero, pois a partir de tal reflexão, os desmembramentos e as escolhas tornam-se fundamentadas e orientadas. Consideramos, aqui, a língua, não como um sistema constituído único e exclusivamente por regras gramaticais, homogeneamente estruturado ou, ainda, como a representação do pensamento, pois tais apreensões desconsideram a perspectiva dos sujeitos usuários e/ou vislumbram sujeitos passivos que, por vezes, teriam a sua compreensão atrelada à percepção ou potencial reconstrução daquilo que se passa na consciência do enunciador-interlocutor (KOCH, 2009; MARCUSCHI, 2008).

A concepção de língua, então adotada, reflete e articula-se a um entendimento que reveste o gênero de agentividade, multiplicidade e orientações comunicativas, em real funcionamento, organização e configurações atrelados ao socialmente assimilado e difundido, ligado ao plano social e às relações intersubjetivamente travadas; parte-se, para tanto, do reconhecimento das ideias desenvolvidas por Bakhtin, no século XX. Ainda que Bakhtin não seja a base teórica adotada, fornece-nos princípios e ideias, postos de maneira elementar, que darão subsídios para uma melhor assimilação daquilo que os gêneros significam.

De acordo com o estudioso, a comunicação humana é concretizada através de "tipos relativamente estáveis de enunciados" (BAKHTIN [1979] 1997, p. 280) que, diretamente ligados a atividades interlocutivas múltiplas, apresentam-se diversos, a partir de rotinas linguisticamente instituídas e identificáveis, integrando, como salienta Marcuschi (2008, p.r49) “[...] a estrutura comunicativa da nossa sociedade”, auxiliando tanto na organização dos sujeitos de linguagem, como também nas atividades que os atores comunicativos efetuam em práticas interativas situadas. Tais rotinas, no entanto, são percebidas e emergem com vistas às interpretações de contextos ${ }^{2}$ ali implicados. Há um plano social,

\footnotetext{
${ }^{2}$ Salientamos, no entanto, que o contexto, na perspectiva aqui adotada, é construído a partir das relações sociointerativas em que os atores sociais, mediante a situação de interlocução, tomam dados elementos como importantes, no intuito de produzir e compreender os discursos (VAN DIJK, 2012).
} 
cultural e cognitivo envolvidos, onde o simbolicamente construído pode ser acessado e delineado, apoiando-se em artefato constituído do/no sujeito de linguagem.

As práticas sociais, via linguagem, podem (re)produzir ou (trans)formar as estruturas modelares, todavia o sujeito inserido no mundo de linguagem não é totalmente autônomo, livre e árbitro de si, pois incorporado está em uma cultura revestida de especificidades e dotada de particularidades, atuando de maneira corpulenta nas práticas adotadas discursivas, não descolados, os atores, de estruturas que lhes envolvem e orientam.

O que há, é uma espécie de coproduções no sistema social, entre continuidades e intervenções, possibilidades e permissões na "forma socioestrutural", onde tudo está interligado e intrinsecamente relacionado, como aponta Emirbrayer (1997), além de valorações e validações no construído e/ou instituído. Contudo, não resultam de mecanismos simplistas, mas na efetivação de relações orientadas, intermediadas por objetivos e intenções, a partir de um mecanismo marcado por apropriação simbólica extremamente apreciado, em interações dialógicas, usos concretos, mediante escolhas adequadamente coordenadas ao socio-histórico, reagindo às demandas, onde a palavra, o dito, o enunciado indicam, de maneira mais concreta, sensível e material "[...] as transformações sociais”3, refletidas em práticas comunicativas.

Poderíamos, então, dizer que existe uma apropriação, em rede, desses sujeitos, quando falamos em práticas comunicativas através gêneros textuais? Revela-se, para nós, no interior das apropriações textuais, um fluxo de transmissão e recepção articulados ao lugar ocupado pelo ser de linguagem, bem como sua percepção e performances linguísticas, o que possibilitaria, no uso, a disseminação de determinadas práticas, legitimações, repetições, modificações e/ou as quebras, considerando-se, todavia, as intervenções, os conhecimentos adquiridos e as experiências comunicativas centradas na práxis, bem como nas escolhas estrategicamente orientadas. O lugar de referência é mediado pelos círculos nos quais, esses agentes, se movem e rodeiam, sabendo-se, porém, que tais “ transações se desenvolvem em redes sociais nem sempre simétricas por natureza: com frequência, os fluxos são "direcionais" em conteúdo e intensidade, com implicações significativas para o acesso diferencial dos atores nos recursos” (EMIRBRAYER, 1997, pg.304), já que vários aspectos da ação dependem não só da inserção social, mas do poder a ela atrelado e validado.

\footnotetext{
${ }^{3}$ Cf. "Marxismo e filosofia da linguagem" (Bakhtin, 2002)
} 
Observa-se, também, que tanto os acessos quanto os próprios usos dos gêneros são dados ora assimétrica ora simetricamente, aos indivíduos no seio das comunidades, em escalas distintas nas rede, já que a apreensão e a manipulação evidenciam os tipos de práticas compartilhadas, formadas e proliferadas em contextos característicos, considerando, para tanto, as relações estabelecidas, o funcionamento de comportamentos linguísticos localizados e fundamentados, em modelos pré-existentes e perpetuados; no entanto, isso não é empecilho para que reconfigurações ocorram, como salienta Cavalcanti (2008, p.26), posto que embora haja uma certa "reprodução", os agentes de linguagem possuem criatividade "[...] e é justamente esse poder inventivo que faz com que os gêneros sejam estruturas maleáveis as quais podem se adequar às possibilidade socio-históricas”.

O que se tem, deste modo, são inter-ações em coletividades, materializadas textualmente e consumidas pela comunidade. As produções estão alicerçadas em atividades específicas, em razão de esferas típicas de circulação, a partir de eventos comunicativos conjuntamente reconhecidos. Aquilo que o gênero faz emergir, está diretamente relacionado ao pertencimento, trânsito e participação efetiva nas/das comunidades de dizer, realizadas por que, antes de tudo, são compostas por indivíduos detentores de saberes que estão conectados entre si, em formas e arranjos, realizando trocas, em uma espécie de transação linguística, devendo, para obter sucesso, compartilhar peças que fazem parte do jogo discursivo no alcance de significações situadas.

Entendemos os gêneros como um recurso, e compactuamos com Farrel (I99i apud Miller, 2012, pg.50) quando sinaliza serem "bens" pertencentes ao campo retórico. Considerando essa indicação, percebemos que tais "bens" só podem ser dados, distribuídos, compartilhados e ganhar existência em detrimento das atividades e práticas relacionais, nas trocas favorecidas e ofertadas pelos sujeitos, em espaços que exijam, propiciem, privilegiem e garantam, efetivamente, sua disseminação no trato comunicativo, nas ações desenvolvidas, formatadas e validadas, mediante ações comuns, representadas e praticadas, por cada um de nós, membros de grupos e coletividades, em direção à uma reciprocidade interlocutiva, onde somos coparticipantes e construtores de vínculos.

Certamente, entender os textos enquanto unidade comunicativa humana, concretizados via gêneros, assumidos como forma de "realizar linguisticamente objetivos específicos em situações particulares" (MARCUSCHI, 2008, p. 154), suas efetivações e movimentos para além do puramente linguístico, abriu um caminho que perpassa desde a compreensão das 
representações sociais até aquilo que comporta aspectos sociocognitivos, possibilitando a esses constructos funcionarem como “[...] materialidade textual a uma determinada interação humana recorrente em um dado tempo e espaço [...]” (MEURER \& MOTTAROTH, 2002, p.II), instaurando "rotinas" comunicativas.

Nossas construções linguísticas fazem, portanto, parte de enquadres comunicativos elaborados societariamente e que não resultam de mera percepção, não são efeito dos órgãos dos sentidos, mas sim edificadas cooperativamente, a partir de interpretações que ganham significações através dos interlocutores que desses espaços sociais fazem parte e nele atuam em parceria.

Para que seja possível atuar nas realidades em que estamos imersos, os gêneros configuram-se como orientadores não só do modo de agir, mas refletem as práticas revestidas de intersubjetividades, bem como formas de ser e conhecer, encontrando amparo na recorrência, na compreensão em como os eventos são socioculturalmente ambientados e apresentam um grau de estabilidade suficientemente reconhecíveis, auxiliando de maneira estratégica nas dinâmicas e coerências comunicativas (BAWARSHI \& REIFF, 2013).

Isto é, ao se atuar discursivamente, escolhemos um modo todo especial para que nossas 636 ações sejam reconhecidas, objetivos possam ser concretizados, a partir de certa familiaridade, dado o acervo compartilhado com os nossos "Outros" comunicativos, com os quais estabelecemos trocas diárias, atravessados pelo senso de reconhecimento da comunidade discursiva, sobre e com a qual atuamos e articulamo-nos, intuídos na construção de universos e versões, a fim de que equilíbrios sejam mantidos e vínculos estabelecidos, recorrendo a uma herança discursivamente acumulada, em laços, como assinala White (apud AZARIAN, 2003), onde sempre haverá "Outros”, mais ou menos distantes, formando-se e formados em longas cadeias, conexões, inclusões e dinâmicas, em trocas.

\section{OS ATORES DE LINGUAGEM, AS REDES SOCIAIS E OS GÊNEROS TEXTUAIS}

Compreende-se que, embora haja aberturas para variáveis individuais e sensibilidade desses constructos em tais acomodações, os gêneros não pertencem a um indivíduo, mas a uma comunidade que, através da linguagem, elabora versões do mundo, como salienta Rodrigues-Leite (2004); conceptualiza-se o mundo em articulação a uma cognição humana 
privilegiada, dadas as suas possibilidades e processamentos, estabelecendo pontes com a ordem social, cultural e histórica provedoras de significações da(s) realidade(s) via intersubjetividades.

Há uma compreensão do papel indispensável desempenhado pelo grupal, posto que não existe transparência nem relação direta, refletidamente estabelecida entre os homens e as coisas mundanas, o que implica o modo como são categorizados, distintamente, os objetos que fazem parte da(s) realidade(s), rotinas e práticas comunicativas, como é, por exemplo, os gêneros, sendo, então, os sentidos negociados e produzidos, como afirma Acosta Pereira (2007, p.1708), pelas "[...] pessoas, que como membros de grupos sociais, se engajam em eventos comunicativos por intermédio da linguagem".

Nos gêneros, reconhecemos, enquanto usuários da língua, seu papel fundamental e característico como "mantenedor de equilíbrios", se o entendermos como orientadores das percepções/construções do socialmente organizado nas produções textuais-discursivas, e, segundo Falcone (2008, p. 65), como "enquadres sócio-interacionais que construímos, ao longo da história, para facilitar nossas relações e torná-las mais dinâmicas e fluidas”, não havendo condições de, no plano discursivo e a cada momento enunciativo, os interactantes formularem novos enquadres em gênero, pois, se fosse assim, certamente, a comunicação tornar-se-ia inviável ou bastante problemática.

Haverá, para tanto, nesse empreendimento interlocutivo, a cooperação de elementos de diversas ordens e naturezas, a fim de que as ações realizadas sejam concretizadas. Dito isso, mente e corpo, subjetividade e objetividade, individual e social, organismo e ambiente precisam estar em trocas constantes, o que conduzirá a uma melhor compreensão em como são dadas as relações entre sociedade, sujeito, linguagem, interação, história e cognição.

Em consonância ao exposto, Marcuschi (2008, p. 93) certifica que:

[...] um texto se dá numa complexa relação entre a linguagem, a cultura e os sujeitos históricos que operam nesses contextos. Não se trata de um sujeito individual e sim de um sujeito social que se apropria da linguagem ou que foi apropriado pela linguagem e a sociedade em que vive.

As configurações textuais sugerem, portanto, um funcionamento que se desenvolve dentro de uma concretude, requerendo que os atores considerem a importância da dinâmica entre os pares na produtividade diversa das práticas sociodiscursivas, o que ancora a criação de expectativas quanto da possibilidade de uma comunicação mútua, 
dotada de significações e valorizada no seio da sua cultura, no estabelecimento de relações que permitam, sociocognitivamente, refletir as práticas/experiências comuns.

O uso dos gêneros assegura a existência das vivências culturais, das relações sociais complexas, do desenvolvimento de uma ação conjunta e das tipificações, já que apenas o conjuntamente instituído e reconhecido, definido em razão de suas funções, "permanece" linguisticamente como herança, como modo de representação e lugar das negociações na construção das categorias, em prol da atribuição de significados, inclusive, no que diz respeito, às próprias configurações genéricas.

O que se pode refletir, é que para a existência de ações de linguagem, é necessário o compartilhamento de conhecimento e a busca na criação/percepção de contextos em torno das atividades verbais organizadas. Estas são dotadas de propósitos comunicativos e passíveis de observação no que Silva (2002, p. 23) concebe como práticas sociais:

[...] o fator de exterioridade social se configura como um elemento intrínseco à atividade discursiva na medida em que se concebe que as formas interacionais da língua, manifestadas em gêneros textuais, atualizadas na sociedade, resultaram (e resultam) de atividades comunicativas humanas, construídas no seio dos eventos comunicativos das esferas sociais (público ou privada), e estas, com seus específicos sistemas socioculturais, organizam e constituem as práticas sociais.

Silva (2002) busca exprimir, através das suas afirmações, não ser possível significar as práticas e os usos como eventos comunicativos que permaneçam estáticos e sejam os mesmos no curso da história das diferentes esferas sociais, mas que, como práticas, são ampliadas, diversificadas e transformadas, pois, de acordo com os próprios usos, atualizações, multiplicações e reformulações acontecem, em razão das relações interlocutivas, suas trocas e permutas.

Os gêneros existem, como salientado por Berkenkotter e Huckin (1995, p. 4), em virtude "das respostas dos agentes a situações recorrentes, que servem para estabilizar a experiência e lhe dar coerência e sentido" ${ }^{4}$, repercutindo as demandas sociocognitivas e interacionais, a partir das atualizações entre interactantes que partilhem uma mesma língua e cultura; são adquiridos através de contextos de socialização, revelando as ideologias presentes, potencializando os ditos e arranjos dos grupos e suas formas de ação (BAWARSHI \& REIFF, 2013).

Observamos, à vista disso, que não somos dados a individualismos absolutos, mas envoltos por um sistema cooperativo-organizacional, interessado na manutenção de certa

\footnotetext{
${ }^{4}$ Tradução nossa: "Generes are dynamic rhetorical forms that are developed from actors responses to recurrent situations and the serve to stabilize experience and give it coherence and meaning."
} 
unidade, em virtude dos compartilhamentos, coparticipações e envolvimento na transmissão, divulgação de práticas de linguagem, legitimamente reconhecidas, que coordenam a vida em sociedade.

Reconhecemos, dessarte, alguma articulação entre o anteriormente dito e aquilo que Fontes \& Eichner (200I) afirmam caracterizar as redes sociais, ao dizerem ser o elo entre os indivíduos e as instituições sociais, fundamentais para e na inserção social (aqui, associamos às práticas comunicativas), ao estruturarem os sujeitos e seus percursos (quando veiculamos situações, propósitos, emergências, arranjos e prestígios), fazendo vir à tona certas condições de realização e ação, dentro das biografias dos indivíduos, das suas histórias (ao estarem inseridos, à nossa concepção, em uma esfera de controle, integração, influência e envolvimento, desses indivíduos, com o maquinário sociodiscursivo) .

Essa incorporação só se torna possível, porque gêneros textuais “estabilizados" circulam e recebem influência dos vieses histórico, social, institucional e técnico (MILLER, 2012); constructos, esses, cercados por normas e convenções. Há, assim, uma potencialidade em tais arquiteturas textuais que as situa local, temporal e socialmente, posto que os usos valorizam, em determinadas circunstâncias e escalas, as conexões que atravessam a comunidade, mas, principalmente, refletem suas práticas e recursos dos quais lançam mão, cada indivíduo na/para apropriação e construção de suas biografias textuais- discursivas.

O que percebemos, então, assim como Emirbrayer ( [1950] 1997), é uma dinâmica nas realidades sociais, não em termos de homogeneidades e estabilizações totais, mas dentro de uma perspectiva que se pauta em específicos de continuidades, dinamicidades e processos, para, então, compreendermos as experiências adquiridas e a agência nos processos interativos, dentro de um contexto percebido, compreendido, validado e processado, sobre o qual se conduzem, os atores, comportam-se e realizam sobre e no mundo, em interdependências, apontando na direção dos outros, dele mesmo, mas também do mundo circundante.

O que, aqui se tem, portanto, é um espelho dos encadeamentos humanos envolvidos em linguagem, no seu uso. Só nos tornamos atuantes, enquanto indivíduos, através do desenvolvimento de tal habilidade, especificamente, nas ligações com os outros, em movimentos cooperativos, o que, em certa medida, é ratificado por Emirbrayer ( [1950] 1997), em Manifesto da Sociologia relacional, quando diz ser de fundamental e indispensável importância valorativa, para a compreensão das ações, estarmos atentos e inclinados nas 
relações de interdependência em lócus específico, naquilo que se solidifica através dos intercâmbios, no conjunto das conexões, de suas somas e dos laços.

Considerando tais somas e convergências, as dádivas ou bens simbólicos que circulam, como creditamos serem os gêneros textuais, em esforços e reforços exercidos pelos diversos atores, Berkenkotter e Huckin (1995, p.4) traçam cinco princípios orientadores de um quadro teórico que conduziria à observação e à manifestação desses constructos; tais fundamentos estariam atrelados ao campo social, às habilidades próprias do humano (habilidades cognitivas) e à cultura circundante, resultando em leitura/compreensão da realidade, apropriação e ação no mundo via gênero, em um enquadre social-cognitivo, em que não há o posto, mas o configurado e compartilhado.

O primeiro deles, é denominado a dinamismo. Berkenkotter e Huckin (op. cit.) expõem que na natureza dos gêneros há vida, pois estão abertos a mudanças, embora funcionem em resposta às situações comunicativas identificadas como "rotinizadas" ou interpretadas como situações-padrão. Isto é, na significação do socialmente construído, há uma "estabilização" que garantiria, aos interlocutores, uma tomada de coerência das formas retóricas. Por outro lado, essa adoção de estabilidade não é empecilho para evolução através do tempo, já que os gêneros atendem às demandas interativas componentes dos espaços de interlocução. Estabilidade e a mudança, em sua constituição fundante, como já sinalizado anteriormente, ocorreriam em razão dos interesses sociocognitivos dos usuários e configurar-se-iam sempre como locais de disputa; de um lado, teríamos a manutenção, a durabilidade e a permanência, já do outro, transformação, mudança e alteração. (BERKENKOTTER E HUCKIN, I995).

Outro aspecto salientado, também por Berkenkotter e Huckin, é a situacionalidade. Neste ponto, a atenção volta-se para o fato de que a compreensão e assimilação dos gêneros está na força do aprendido e apreendido por profunda imersão cultural; valores e comportamentos são identificados e tomados como necessários em resposta às situações experienciadas, pois o aprendizado, adquirido ao longo do tempo, em relação aos gêneros, faria parte do "conhecimento de gênero", isto é, um saber a respeito das organizações textuais que são sistematicamente incorporadas, dada a localização dos interactantes em ambiente cultural, pois como ressalta Cavalcanti (2008), as práticas relacionadas às ações dentro da sociedade, configuram repertórios de conhecimento, sendo, no entanto, esse 
repertório e as ações advindas de tais saberes, assim como as ações resultantes das práticas, desconectadas, muitas vezes, de uma motivação consciente.

O que parece ser evidenciado para Berkenkotter e Huckin (apud BAWARSHI \& REIFF, 2013, p.I04) é o fato de se incorporar "dinamicamente os modos de conhecer, ser e agir de uma comunidade", refletindo de maneira mais incisiva o fato de que as próprias relações sociais, bem como as estruturas linguísticas, que comportam as práticas, através do compartilhamento manifesto entre seus membros, gerarem grupalmente a emergência de textos específicos, que reproduzam estruturas aprendidas cotidianamente e encontram amparo no que se relaciona à forma e ao conteúdo.

Os teóricos, considerando essa relação, propõem a existência de uma estrutura fundante sobre a qual "repousaria” um conteúdo apropriado às situações, aos propósitos que emergem e solicitam, contextualmente, determinadas configurações, arranjos ou características mais específicas, possivelmente adquiridos no curso das práticas comunicativas instituídas historicamente, em um processo que se assemelha em termos de Emirbrayer (1997) a uma concepção de mundo e de realidade, abertos às relações, aos processos e às práticas, produzindo efeitos.

Berkenkotter e Huckin (1995) reforçam, no entanto, que aquilo que constitui o 641 verdadeiro aprendizado e conhecimento de gênero é “[...] não apenas o conhecimento das convenções formais, mas o conhecimento do tópico apropriado, bem como dos detalhes relevantes" (p.I4). Haveria, de tal modo, um tempo determinado e espaço apropriado para o aparecimento de certas configurações ou de características mais formais, assim como a existência de um conhecimento de fundo (de uma disciplina, de uma comunidade, de mundo...), além de um senso de assimilação, a fim de que os agentes comunicativos alcancem seu(s) propósito(s) retórico(s), levando a uma compreensão de que tais sistematizações e modos particulares do uso da língua são "formas culturais e cognitivas de ações social corporificadas" (MARCUSCHI, 2008, p.156), em sistemas que não estão e não são desincorporados do comunicativo, do relacional, das trocas e das transações.

Haveria, ainda, no que se refere à própria prática e uso dos gêneros, aquilo que Berkenkotter e Huckin (1995) denominam dualidade de estrutura; propõe-se uma relação direta entre os agentes, as estruturas sociais e seus arranjos, levando à existência de um

\footnotetext{
${ }^{5}$ Tradução nossa: "[...] what constitutes true genre knowledge is not just a knowledge of formal conventions but a knowledge of appropriate topics and relevant details as well”.
} 
diálogo constante entre essas duas forças, pois ao mesmo tempo em que se constituem enquanto "esferas", são constituídos em articulação. O que se pode inferir, é que tal configuração sugere um não completo domínio das estruturas sobre os agentes interacionais, como se elas fossem dadas a priori, mas também não há possibilidade de os agentes interlocutivos investirem, exclusivamente, em suas subjetividades, na efetivação de práticas linguajeiras, já que existiriam condições mais ou menos determinadas a guiarem suas posturas.

Esta configuração poderia, então, levar-nos a compreender os gêneros tanto como modificadores de estruturas, em razão da sua dinamicidade, quanto como uma espécie de reflexo da existência de organizações orientadoras das ações humanas. Percebe-se que, se por um lado há direcionamentos e "padrões" a serem replicados, dada a nossa condição sociocultural, também é possível realizar adaptações, mediante as necessidades comunicativas. Elas auxiliam a (re)configurar o quadro das estruturas socialmente convencionadas, integrantes de uma realidade discursivamente elaborada, e refletidas nas produções dos gêneros.

A partir do direcionamento de Giddens (2003), ao considerar que as estruturas são constituídas e existem como resultado do uso que as pessoas fazem de 'regras e recursos', Acosta Pereira (2007, p.I7II) esclarece que:

[...] As regras são as normas, as convenções e os significados através dos quais as pessoas se orientam ao compreender e desempenhar ações sociais. Os recursos são as posses e as capacidades que as pessoas têm que lhes permitem exercer controle sobre o meio ambiente e sobre outros indivíduos.

Isto é, quando tratamos dos aspectos relacionados aos gêneros, bem como da agentividade e a relação com estrutura, consideramos as experiências no âmbito social, a capacidade interpretativa e compreensiva de realidades e a forma como esses agentes discursivos lidam com o uso linguístico, a partir das representações das estruturas, que são simbólicas, mas às quais são atribuídas, a uma ou a outra, substancialidade e ação estratégica, em resposta às exigências, correspondências, convenções e tradições, de acordo com as demandas; como afirma Miller (2012, p.29), a(s) ação(-ões) empregada(s) não decorre $(m)$ em virtude à uma objetividade, materialidade, mas "baseada em (e guiada por) sentido e não em causas materiais; no centro da ação, encontra-se um processo de intepretação". 
Certamente, e em paralelo a estes dizeres, estabelece-se uma relação com fatores relacionados à nossa socialização, em uma prática que nos permite uma associação a Giddens (2003), articulando a compreensão de que, nessas produções de linguagem há reproduções de práticas cotidianas, pois " componentes de interação sempre gravitam em torno das relações entre os direitos e as obrigações 'esperadas' pelos participantes[...]" (p.35), ou seja, utilizar-se de constructos simbólicos socialmente elaborados, bem como recorrer a práticas "estabilizadas", ganham contornos e articulam-se em uma dialética entre saberes sociais $\mathrm{e}$ individuais, mas mais que isso, ligam-se a sistemas ou representatividades que, ao mesmo tempo, restringem e facilitam a vida discursiva dos interlocutores.

Berkenkotter e Huckin (1995) unem às noções aqui apresentados, domínios da comunidade ou convenções das comunidades discursivas. Para eles, as operações realizadas nos gêneros, muito dizem respeito em como uma comunidade acorda os aspectos epistemológico, ideológico e ontológico. Ao acessarmos os gêneros, eles podem revelar como os grupos discursivos concebem o mundo circundante, mas também como os textos produzidos socialmente carregam consigo intenções, valores, propósitos e verdades estabelecidos na história das comunidades através de mecanismos próprios, sendo estes, larga ou explicitamente, difundidos ou apreendidos/aprendidos participativamente, em práticas interativas, como salienta o próprio Giddens (2003), produzidas e reproduzidas na interação entre “os atores (que) vivem em contextos situados” (op citi., p.394), e por tais regularidades, reproduções, intenções e propósitos, atuam reflexivamente.

Essas inclinações e percepções conduzirão a práticas interativas mais ou menos apropriadas e que possibilitarão ao usuário, como afirmam os teóricos (BERKENKOTTER \& HUCKIN, 1995, p. 24), "reconhecer os padrões disponíveis através do qual podemos agir a qualquer momento" 6 . Por certo, estar-se-á amparado em uma compreensão que é dada a partir das situações de interlocução e nas representações concebidas pelas experiências, unindo os interactantes $e$ os fazendo construir conjuntamente ações discursivas, articuladas nos espaços em que estão vinculados, a eles conectando-se, a fim de atenderem interesses comunicativos, em movimentos realizados coletivamente.

\footnotetext{
${ }^{6}$ Tradução nossa: "[...] we constantly monitor our actions and recognize the avaliable patterns throught wich we might act any given momente"
} 
Fazendo um paralelo com aquilo que Recuero nos diz (2014), não haveria a possibilidade de expansão e formação de uma grande redes, neste caso, redes de interlocução, sem a presença e potencialidade de dois elementos fundamentais e indispensáveis: os atores (pessoas, instituições ou grupos), os chamados "nós", e as interligações, por eles realizadas, suas conexões e estruturação; vivemos, de fato, dentro de um teia cheia de emaranhados, a partir das trajetórias (BARBOZA, 2019), ao que também acrescentaria, disponibilidades, direcionamentos e objetivos, em mobilidades e plasticidade, dentro de uma lógica estrutural.

É importante ressaltar que essas interpretações encontram-se fundamentadas nas relações intersubjetivas, das rotinas ou recorrências, e que chegam até nós através de experiências discursivas, de construções sociocognitivamente elaboradas, de constructos ordenados em um tempo que é situado histórica e culturalmente, refletidos, como viemos apontando, nos usos dos gêneros.

A partir de construções que refletem práticas direcionadas, há um arranjo efetivado pelo meio social, articulado à memória, às vivências e aos vínculos com outros, refletindo, à vista disso, práticas sociais, modos de saber, conhecer e atuar, ligando-se à cognição, uma vez que "a forma como conhecemos e a forma como agimos estão mutuamente relacionados" (BAWARSHI 1994 apud BAWARSHI \& REIFF, 2013, p. 105). Esta cognição é situada, pois além de não ser concebida como individual, mas sim tomada como uma construção social, amparada nas interações, está intimamente interconectada ao fato de que intenções, criatividade e valores estão presentes nas realizações comunicativas contextualizadas, para a formação de significações no mundo.

Lidamos, assim, com uma teia em que se costuram ações de ordem cognitiva, histórica, cultural e social em função dos intercâmbios, onde participantes, ali circunscritos e em trabalho cooperativo, modelam os significados evocáveis de uma realidade socialmente interpretável e convencionada na/pela linguagem, pois o mundo que se configura e ganha relevos é construído fora de uma ordem "natural", e é "fruto" de acessos do agir intersubjetivista (MARCUSCHI, 2004, p. 2).

Os gêneros textuais configurar-se-iam, enquanto práticas discursivas, na condição de que as "mentes individuais não aprendem uma computação abstrata, mas estão aprendendo a compreender um processo historicamente situado, compreendido e transformado pelo indivíduo ao longo das suas histórias de vida" (KOCH \& CUNHA- 
LIMA, 2005, p. 279), sem limites bem estabelecidos entre o que se processa individualmente ou socialmente, sem segmentações fixamente ordenadas, onde esses mesmos sujeitos operam no tráfego entre saberes individuais e sociais, nas mais diversas práticas de linguagem, que se (re)constroem/emergem via gêneros.

Eles integram uma categoria que comporta parte das produções humanas, são adquiridos mediante a atuação mútua de agentes interlocutivos em um contexto, de um modo que não há como desenvolver práticas comunicativas em isolamento. As nossas compreensões/significações, como ressalta Marcuschi (2007, p. 80), resultam "de interações sociais no interior da cultura e da história" através de acordos estipulados, ainda que concebidos tacitamente.

Podemos creditar que ao serem estabelecidos, estabilizados, compartilhados e passados à diante, os textos, configurados em gêneros, constituem em uma espécie de aliança entre aqueles a que eles recorrem; vemo-nos, pois, envolvidos em sistemas de trocas, dentro de um simbolismo, em redistribuições, a partir do uso, o que muito faz lembrar os processos e significações da "dádiva”, em Mauss ( [1950] 2007), em sua tríplice caracterização do "dar, receber e retribuir", posto que esse bem compartilhado e amplamente difundido, expande ou retrai, a partir de uma obrigação coletiva em três movimentos: doação, recebimento e devolução, sejam eles bens simbólicos ou materiais.

Vemos uma integração entre os sujeitos que dispõem de conhecimento de gênero, como apontado anteriormente, articulada à recepção, reconhecimento e intervenção quanto ao contato com determina estrutura textual e sua função específica, bem que se retribui, quando, ao estar centrado em determinadas relações e espaços, é propagado, para os menos experientes, desembocando em saber, funcionalidade e valor, enxergando, como Mauss ( [1950] 2007) que aquilo que transita tem poder/influência sobre os agentes, assim como os acessos e lugares que podem ser ocupados por esses atores, dentro da estrutura e espaços sociais em curso. Temos, nada menos ou nada mais, do que o relacional sendo feito e tecido nas conexões estabelecidas e estabilizadas, dentro de uma ordem coletivamente sedimentada, afim de que as redes possam ser mantidas textual, discursiva e socialmente.

\section{CONSIDERAÇÕES FINAIS}

Ao falarmos e explicitarmos sobre gêneros textuais e as associações em um universo relacional pautado, indubitavelmente, nas interlocuções, torna-se válido ressaltar alguns 
pontos interessantes e que refletem, mais pontualmente, acerca daqueles e do movimento, em rede, feito em sociedade:

I) Ao validarmos todos os aspectos, trazidos no texto, referentes aos gêneros, compreendemos que quanto mais conectados estão os atores, e suas interações tornam-se mais dinâmicas, direcionadas e endereçadas, maior a possibilidade de circulação dos constructos textuais, seu trânsito, uso e acesso, se os entendermos dentro de um quadro maior, especificamente, para a comunicação verbal, enquanto atividade social, histórica e cognitiva;

II) Os gêneros desempenham função primordial no fortalecimento de laços, ampliação e circulação saberes, mas também exercem impacto na hierarquia de poder, em razão das estruturas pelas quais movem; são fenômenos históricos, fruto de um trabalho desenvolvido coletivamente e, por essa mesma coletividade, legitimados nas interações, sendo fundamentais para incluir e firmar, os sujeitos, nas práticas comunicativas;

III) As categorizações dos textos (gêneros) podem ser concebidas como "bens simbólicos" que estruturam a vida em sociedade e, sem os quais, as rotinas interlocutivas, seriam amplamente dificultadas. Eles garantem um senso de convenção, facilitador das interações entre os atores e as trajetórias discursivoenunciativas incorporadas;

IV) Enquanto entidade socio-discursiva, funcionam como elos que tipificam, nas palavras de Miller (2012), o recorrente, a partir das investidas entre os atores e suas pretensões de dizer, fundamentais para/na integração entre estes e as instituições, em espaço e tempo.

\section{REFERÊNCIAS BIBLIOGRÁFICAS}

ACOSTA PEREIRA, Ricardo. Gêneros Midiáticos Multimodais - Uma Discussão sobre Letramento Visual, Ensino e Práticas Sociais. In: IV Simpósio Internacional de Estudos de Gêneros Textuais - SIGET, 2007, Tubarão - SC. Anais do IV Simpósio Internacional de Estudos de Gêneros Textuais - SIGET. Tubarão - SC: UNISUL, 2007.

AZARIAN, Reza. The general sociology of Herrison White. Estocolmo: Täbykopia AB, 2003.

BAKHTIN, Mikhail. Estética da criação verbal. (Trad. Maria Ermentina Galvão). [1979]. São Paulo: Martins Fonte, 1997.

BAWARSHI, Anis S.; REIFF, Mary Jo. Gêneros - história, teoria, pesquisa e ensino. Tradução Benedito Gomes Bezerra. I ${ }^{a}$ ed. São Paulo: Parábola, 2013.

BERKENKOTTER, Carol; HUCKIN, Thomas. Rethinking genre from a sociocognitive perspective. In: _. Genre knowledge in disciplinary communication: cognition/culture/power. Hillsdale, New Jersey: LEA - Lawrence Erlbaum Associates, Publishers. 1995. p. oI- 25. 
CAVALCANTI, Davi Barbosa. Quem são os grupos de direita que ganharam as ruas do País? Uma análise de redes com ênfase nos atores e pautas do Movimento Brasil Livre e do Vem pra Rua. ıoof. Tese (Doutorado em Ciência Política) - Programa de Pós-graduação em Ciência Política da Univesidade Federal de Pernambuco, Recife, 2019.

CAVALCANTI, Maria Clara C. Multimodalidade e argumentação na charge.iozf. Dissertação (Mestrado em Linguística) - Programa de Pós-graduação em Letras da Universidade Federal de Pernambuco, Recife, 2008.

EMIRBAYER, Mustafa. Manifest for a relational sociology. The American Journal of Sociology, v. 103, n. 2, p. 281-317 Sep. 1997.

FALCONE, Karina. (Des)legitimação: ações discursivo-cognitivas para o processo de categorização social. 682f. Tese (Doutorado em Linguística) - Programa de Pós-graduação em Letras da Universidade Federal de Pernambuco, Recife,20o8.

FONTES, Breno Augusto Souto Maior; EICHNER, Klaus. Sobre a estruturação de redes sociais em associações voluntárias: estudo empírico de organizações não-governamentais da cidade do Recife. Sociedade e Estado. Brasília, v.16, n. I-2, p. I86-221, jun/dez. 200 .

GIDDENS, Anthony. A constituição da sociedade. São Paulo: Martins Fontes, 2003.

KOCH, Ingedore G. Villaça. Desvendando os segredos do texto. $6^{a}$ ed. São Paulo: Cortez, 2009 .

$\mathrm{KOCH}$, Ingedore G. Villaça; CUNHA-LIMA, Maria Luiza. Do cognitivismo ao sociocognitivismo In: MUSSALIM, Fernanda; BENTES, Anna Christina. Introdução à Linguística: Fundamentos epistemológicos, vol.3, $3^{\mathrm{a}} \mathrm{ed}$. São Paulo: Cortez, 2005.

MARCUSCHI, Luiz Antônio. Produção textual, análise de gêneros e compreensão. São Paulo: Parábola Editorial, 2008.

Lucerna, 2007.

Cognição, linguagem e práticas interacionais. Rio de Janeiro:

A construção do mobiliário do mundo e da mente: Linguagem, cultura e categorização. Juiz de fora: UFJF, 2004.

MAUSS, Marcel. Sociologia e Antropologia. (Trad. Paulo Neves). [1950]. São Paulo: Cosac Naify,2007.

MEURER, José Luiz e MOTTA-ROTH, Désirée (orgs.). Gêneros Textuais- reflexões e ensino. São Paulo: EDUSC, 2002.

MILLER, Carolyn R. Gênero textual, agência e tecnologia. São Paulo: Parábola, 2012. 
RECUERO, Raquel. Contribuições da Análise de Redes Sociais para o Estudo das Redes Sociais na Internet: $O$ caso da hashtag \#Tamojuntodilma e \#CalaabocaDilma. Revista Fronteiras (Online). v.16, p.I-22, 2014.

RODRIGUES-LEITE, Jan Edson. Cognição e linguagem na elaboração do saber. Investigações (Recife), Recife, v.oI, n.oI, p. 23-45, 2004.

SILVA, Jane Quintiliano Guimarães. Um estudo sobre o gênero carta pessoal: das práticas comunicativas aos indícios de interatividade na escrita dos textos. 2002. 209f. Tese (Doutorado em Linguística) - Faculdade de Letras da UFMG, Universidade Federal de Minas Gerais, Belo Horizonte, 2002. 